\title{
SELF-REGULATORY EFFICACY SISWA SMP MELALUI PEMBELAJARAN PENEMUAN TERBIMBING
}

\author{
Riska Novia Sari \\ Program Studi Pendidikan Matematika, Fakultas Keguruan dan Ilmu Pendidikan, \\ Universitas Riau Kepulauan, Batam, Indonesia \\ e-mail: riskanovia30@gmail.com
}

\begin{abstract}
Abstrak
Penelitian ini bertujuan untuk mengetahui self-regulatory efficacy siswa melalui penerapan pembelajaran penemuan terbimbing. Penelitian ini merupakan penelitian quasi experiment dengan desain kelompok kontrol non ekivalen. Populasi penelitian adalah siswa kelas IX SMPN 3 Lembang. Sampel terdiri dari kelas $\mathrm{IX}_{\mathrm{A}}$ sebagai kelompok kontrol dan kelas $\mathrm{IX}_{\mathrm{B}}$ sebagai kelompok eksperimen. Instrumen yang digunakan yaitu angket/skala self-regulatory efficacy. Data dianalisis menggunakan uji beda dua proporsi. Hasil penelitian menunjukkan bahwa tidak terdapat perbedaan proporsi keyakinan kemandirian belajar yang signifikan antara siswa yang belajar melalui pembelajaran penemuan terbimbing dengan siswa yang belajar melalui pembelajaran konvensional.
\end{abstract}

Kata kunci: self-regulatory efficacy, pembelajaran penemuan terbimbing

\begin{abstract}
This study aims to determine the self-regulatory efficacy of students through the application of guided discovery learning. This research is a quasi experiment research with non equivalent control group design. The population of the study were students of class IX SMPN 3 Lembang. The sample consists of class IXA as the control group and the IXB class as the experimental group. The instrument used is a self-regulatory efficacy questionnaire. The data were analyzed using different test of two proportions. The results showed that there was no significant difference in the proportion of selfregulatory efficacy between students learning through guided discovery with students learning through conventional learning.
\end{abstract}

Keywords: self-regulatory efficacy, guided discovery learning

\section{Pendahuluan}

Salah satu kemampuan afektif siswa yang penting dalam pembelajaran matematika yaitu kemandirian belajar. Zimmerman (2002) mendefinisikan kemandirian belajar sebagai proses belajar yang terjadi karena pengaruh dari pemikiran, perasaan, strategi, dan perilaku sendiri yang berorientasi pada pencapaian tujuan. Schunk \& Zimmerman (Sumarmo, 2013) menyatakan kemandirian belajar memuat tiga karakteristik utama yaitu merancang tujuan, memilih strategi, dan memantau proses kognitif dan afektif yang berlangsung ketika seseorang menyelesaikan suatu tugas akademik.

Mengetahui strategi kemandirian belajar tidaklah cukup, siswa haruslah memiliki keyakinan mereka dapat menggunakan strategi tersebut secara efektif. Dalam kehidupan individu memiliki keyakinan merupakan hal yang sangat penting. Keyakinan merupakan 
pertimbangan seseorang terhadap kemampuannya mengorganisasikan dan melaksanakan tindakan-tindakan yang diperlukan untuk mencapai performansi tertentu. Fas, et.al juga menyatakan bahwa keyakinan sebagai tingkat kepercayaan siswa terhadap kemampuan dirinya untuk menyelesaikan tugas-tugas yang spesifik (Prabawanto, 2013). Keyakinan dan kemandirian belajar memiliki hubungan yang erat. Hal ini didukung oleh pendapat Tilman \& Weiss (2000), menyatakan bahwa siswa yang mandiri adalah siswa yang mempunyai keyakinan atau kepercayaan diri (self-efficacy) yang tinggi. Didukung oleh Sumarmo (2013) yang menemukan bahwa siswa yang memiliki self-efficacy tinggi menunjukkan kemandirian belajar yang tinggi juga.

Keyakinan kemandirian belajar berasal dari istilah self-efficacy for self-regulated learning/self-regulatory efficacy. Usher, et.al (2011) menyatakan keyakinan kemandirian belajar yaitu keyakinan siswa untuk dapat menggunakan kemampuannya mengelola pembelajaran, artinya siswa dapat mengimplementasikan strategi kemandirian belajar di sekolah. Hal yang sama diungkapkan Joo, et.al (2000) bahwa "self-efficacy for self-regulated learning refers to student's perceived capability to use a variety of self regulated learning strategies such as self-monitoring, self-evaluation, goal setting and planning, selfconsequences, and environmental restructuring”. Artinya keyakinan kemandirian belajar yaitu kemampuan siswa untuk menggunakan strategi kemandirian belajar yang beragam diantaranya, memantau, mengevaluasi diri, menetapkan tujuan dan perencanaan, konsekuensi, dan menata lingkungan dalam menghadapi suatu tugas akademik.

Keyakinan kemandirian belajar merupakan faktor penting dalam menentukan motivasi dan prestasi akademik siswa pada semua level sekolah (Usher \& Pajares 2008). Hasil penelitian Joo, et.al (2000) menunjukkan bahwa keyakinan kemandirian belajar berpengaruh positif terhadap hasil kinerja yang berhubungan langsung dengan kemampuan akademik siswa dan kemampuan menggunakan internet. Selain itu, hasil penelitian Joet, et.al (2011) mengindikasikan keempat sumber keyakinan (pengalaman keberhasilan, pengalaman perumpamaan, persuasi verbal, dan kondisi psikologis dan emosi) mempengaruhi keyakinan kemandirian belajar dalam matematika, serta terdapat perbedaan gender, dimana siswa lakilaki memiliki keyakinan kemandirian belajar yang lebih tinggi daripada siswa perempuan. Hasil penelitian Usher \& Pajares (2008) melaporkan siswa sekolah dasar memiliki keyakinan kemandirian belajar yang lebih tinggi dibandingkan siswa sekolah menengah dan sekolah tinggi. Hal ini dipengaruhi oleh faktor keyakinan, konsep diri, orientasi tugas, kecemasan, dan prestasi. 
Usher \& Pajares (2008), Joet, et.al (2011) menyarankan untuk penelitian selanjutnya agar mengukur keyakinan kemandirian belajar siswa pada konteks akademik yang lebih spesifik. Hal ini karena keyakinan kemandirian belajar akan terprediksi secara efektif ketika diuji dalam tes akademik khusus, contohnya keyakinan kemandirian belajar pada pelajaran matematika. Dalam penelitian ini keyakinan kemandirian belajar siswa dilihat dari keyakinan siswa dapat mengerjakan sendiri dengan benar tugas-tugas yang berkaitan dengan kemampuan penalaran dan komunikasi matematis.

Selanjutnya, untuk mengembangkan keyakinan kemandirian belajar siswa Corte merumuskan tiga komponen yang harus dilakukan yaitu "...realistic and challenging tasks; variation in teaching methods including teacher modelling, guided practice, small group work and whole class instruction; and classrooms that foster positive dispositions towards learning mathematics"(Darr \& Fisher, 2004). Pada pembelajaran penemuan terbimbing dalam penelitian ini siswa bekerja dalam kelompok kecil yang terdiri dari siswa berkemampuan heterogen (tinggi, sedang, dan rendah), berdasarkan pendapat Corte diharapkan keyakinan kemandirian belajar siswa dapat meningkat. Dalam pembelajaran penemuan terbimbing guru menyediakan masalah dan mendorong siswa untuk menyelesaikan masalah tersebut secara berkelompok.

Pembelajaran penemuan merupakan salah satu pembelajaran berlandaskan paradigma konstruktivisme (Rooney, 2009). Disamping itu, pembelajaran penemuan ini sejalan dengan tujuan pembelajaran matematika, dimana menurut Gulo (Trianto, 2009) pembelajaran penemuan merupakan rangkaian kegiatan belajar yang melibatkan secara maksimal seluruh kemampuan siswa untuk mencari dan menyelidiki secara sistematis, kritis, logis, analitis, sehingga siswa mampu merumuskan sendiri penemuannya dengan penuh percaya diri. Terlihat bahwa pembelajaran penemuan dapat meningkatkan keyakinan siswa akan kemampuannya karena mereka menemukan sendiri konsep materi yang dipelajari.

\section{METODE PENELITIAN}

Jenis penelitian yang digunakan yaitu penelitian kuasi eksperimen. Pada kuasi eksperimen, subjek tidak dikelompokkan secara acak, tetapi peneliti menerima keadaan subjek apa adanya (Ruseffendi, 2010). Pertimbangan penggunaan desain penelitian ini adalah untuk mengefektifkan waktu penelitian supaya tidak membentuk kelas baru yang akan menyebabkan perubahan jadwal yang telah ada. Populasi penelitian adalah seluruh siswa kelas IX pada salah satu SMPN di Kabupaten Bandung Barat. Dari populasi tersebut dipilih 
dua kelas sebagai sampel penelitian yang ditentukan berdasarkan purposive sampling dengan tujuan agar penelitian dapat dilaksanakan secara efektif dan efisien terutama dalam hal pengawasan, kondisi subyek penelitian, waktu penelitian yang ditetapkan, kondisi tempat penelitian serta prosedur perizinan.

Instrumen untuk mengumpulkan data pada penelitian ini disusun dalam bentuk angket/kuisioner keyakinan kemandirian belajar. Instrumen keyakinan kemandirian belajar dikonstruksi dan dikembangkan oleh peneliti dengan mengacu pada kuesioner yang dikembangkan oleh Scristia (2014), dan dengan mengacu pada saran Usher \& Pajares (2008), Joet, et.al (2011) bahwa untuk penelitian selanjutnya agar mengukur keyakinan kemandirian belajar siswa pada konteks akademik yang lebih spesifik. Pengembangan instrumen ini dilakukan melalui beberapa tahap, yaitu tahap pembuatan, revisi, dan tahap ujicoba instrumen. Uji coba instrumen dilakukan untuk melihat layak atau tidak suatu instrumen digunakan dalam penelitian.

Skala keyakinan kemandirian disusun dalam bentuk skala likert, dengan empat skala pilihan keyakinan, jika siswa menjawab pilihan jika siswa menjawab pilihan (a) yang berarti "sangat yakin" dapat mengerjakan sendiri dengan benar diberi skor 4, jika siswa menjawab pilihan (b) yang berarti "yakin" dapat mengerjakan sendiri dengan benar diberi skor 3, jika siswa menjawab pilihan (c) yang berarti "tidak yakin" dapat mengerjakan sendiri dengan benar diberi skor 2, jika siswa menjawab pilihan (d) yang berarti "tidak yakin" dapat mengerjakan sendiri dengan benar diberi skor 1. Dalam penelitian ini tidak menggunakan pilihan jawaban netral $(\mathrm{N})$, hal ini bertujuan untuk menghindari kecenderungan siswa tidak berani memihak terhadap pernyataan-pernyataan pada angket keyakinan kemandirian.

Setelah diperoleh skor keyakinan kemandirian belajar, dilanjutkan dengan menghitung persentase jawaban siswa pada masing-masing indikator. Selanjutnya untuk menjawab hipotesis yaitu:

$\mathrm{H}_{0} \quad$ : Tidak terdapat perbedaan proporsi keyakinan kemandirian belajar siswa yang belajar melalui pembelajaran penemuan terbimbing dengan siswa yang belajar melalui pembelajaran konvesional.

$\mathrm{H}_{1} \quad$ : Terdapat perbedaan proporsi keyakinan kemandirian belajar siswa yang belajar melalui pembelajaran penemuan terbimbing dengan siswa yang belajar melalui pembelajaran konvesional.

Pengujian hipotesis dilakukan uji perbedaan perbedaan proporsi dengan taraf signifikan $\alpha=0,05$. Kriterianya yaitu terima $\mathrm{H}_{0}$ jika $-Z_{\alpha / 2}<z<Z_{\alpha / 2}$. Dari hasil perhitungan uji beda dua proporsi akan dapat dilihat analisis perbedaan proporsi keyakinan 
kemandirian belajar siswa yang belajar melalui pembelajaran penemuan terbimbing dengan siswa yang belajar melalui pembelajaran konvesional.

\section{HASIL PENELITIAN DAN PEMBAHASAN}

Keyakinan kemandirian belajar siswa diukur dengan menggunakan skala keyakinan kemandirian. Pengisian skala keyakinan kemandirian belajar dilakukan setelah postes, yaitu pada pertemuan ke-9. Skala keyakinan kemandirian belajar diberikan kepada siswa kelompok eksperimen dan kelompok kontrol. Keyakinan kemandirian belajar yang menjadi fokus dalam penelitian ini yaitu keyakinan kemandirian siswa dalam menyelesaikan tugas-tugas yang berkaitan dengan soal kemampuan komunikasi dan penalaran matematis dengan benar.

Keyakinan kemandirian belajar siswa untuk menyelesaikan tugas-tugas yang berkaitan dengan kemampuan komunikasi matematis terdiri dari dua indikator yaitu keyakinan kemandirian siswa dalam menyelesaikan tugas-tugas yang berkaitan dengan "Menyatakan suatu situasi atau masalah matematik atau kehidupan sehari-hari ke dalam bentuk gambar, diagram, bahasa atau symbol matematika; atau model matematika" dengan benar. Selanjutnya, keyakinan kemandirian siswa dalam menyelesaikan tugas-tugas yang berkaitan dengan "mengekspresikan, mendemonstrasikan serta melukiskan ide-ide matematika ke dalam bentuk gambar, tabel, grafik atau model matematika lain" dengan benar.

Keyakinan kemandirian belajar siswa untuk menyelesaikan tugas-tugas yang berkaitan dengan kemampuan penalaran matematis terdiri dari dua indikator yaitu keyakinan kemandirian siswa dalam menyelesaikan tugas-tugas yang berkaitan dengan "Memberi penjelasan terhadap model, fakta, sifat, hubungan, atau pola yang ada" dengan benar. Selanjutnya, keyakinan kemandirian siswa dalam menyelesaikan tugas-tugas yang berkaitan dengan "Memeriksa validitas argumen, membuktikan, dan menyusun argumen yang valid." dengan benar.

Berikut ini disajikan distribusi proporsi keyakinan kemandirian belajar siswa kelompok eksperimen dan kelompok kontrol:

\section{Tabel 1}

Distribusi Proporsi Keyakinan Kemandirian Belajar

\begin{tabular}{c|c|c}
\hline Indikator & \% Eksperimen & \% Konvensional \\
\hline 1 & 62,5 & 58,3 \\
\hline 2 & 66 & 60,3 \\
\hline 3 & 61,2 & 57,9 \\
\hline 4 & 71,1 & 67,8 \\
\hline Keseluruhan & 65,2 & 61 \\
\hline
\end{tabular}


Berdasarkan Tabel 1, proporsi secara keseluruhan keyakinan kemandirian belajar siswa kelompok eksperimen dan kelompok kontrol yaitu masing-masingnya 65,2 dan 61 . Artinya dari keseluruhan siswa kelompok eksperimen 65,2\% siswa sudah memiliki keyakinan kemandirian belajar. Sedangkan siswa kelompok kontrol memiliki keyakinan kemandirian belajar 4,2\% lebih rendah daripada siswa kelompok eksperimen. Terlihat bahwa proporsi keyakinan kemandirian belajar siswa kedua kelompok tidak jauh berbeda. Untuk lebih jelasnya perbandingan proporsi keyakinan kemandirian belajar siswa dapat dilihat pada gambar berikut:

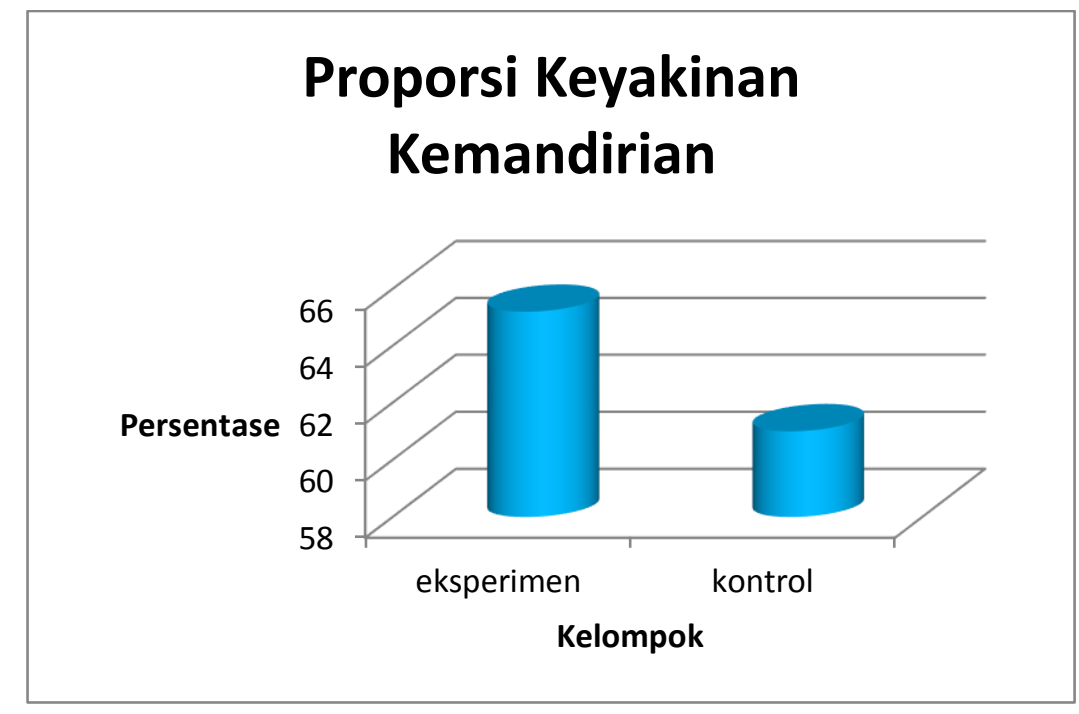

\section{Gambar 1}

\section{Perbandingan Keyakinan Kemandirian Belajar Siswa}

Gambar 1 menunjukkan proporsi keyakinan kemandirian belajar siswa kelompok eksperimen yang belajar melalui pembelajaran penemuan terbimbing tidak jauh berbeda dengan siswa kelompok kontrol yang memperoleh pembelajaran konvesional. Untuk mengetahui apakah proporsi keyakinan kemandirian belajar siswa tidak berbeda secara signifikan pada kedua kelompok dilakukan uji perbedaan proporsi keyakinan kemandirian belajar siswa.

Berikut rangkuman hasil uji perbedaan dua proporsi keyakinan kemandirian belajar siswa:

Tabel 2

Hasil Uji Beda Dua Proporsi Keyakinan Kemandirian Belajar Siswa

\begin{tabular}{c|c|c|c|c|c|c}
\hline $\mathrm{n}_{1}$ & $\mathrm{n}_{2}$ & $\mathbf{X}_{\mathbf{1}}$ & $\mathbf{X}_{\mathbf{2}}$ & $\mathbf{Z}_{\text {tabel }}$ & $\mathbf{z}$ & Ket \\
\hline 468 & 504 & 256 & 246 & $Z_{\alpha} / 2=1,96$ & 1,84 & Terima $\mathrm{H}_{0}$ \\
\hline
\end{tabular}


Berdasarkan hasil perhitungan, terlihat pada Tabel 2 diperoleh $z=1,84$ yang artinya $-1,96<z=1,84<1,96$, maka $\mathrm{H}_{0}$ diterima. Hal ini berarti tidak terdapat perbedaan proporsi atau persentase keyakinan kemandirian belajar secara signifikan antara siswa yang belajar melalui pembelajaran terbimbing dengan siswa yang belajar melalui pembelajaran konvensional.

Berikut distribusi proporsi masing-masing indikator skala keyakinan kemandirian belajar untuk kelas eksperimen dan kelas kontrol.

\section{Tabel 3}

\section{Distribusi Proporsi Keyakinan Kemandirian Belajar Siswa Berdasarkan Indikator}

\begin{tabular}{|c|c|c|c|c|c|c|c|c|c|c|c|}
\hline \multirow[t]{2}{*}{ Indikator } & \multirow[t]{2}{*}{ Ket } & \multicolumn{5}{|c|}{ Kelompok Eksperimen } & \multicolumn{5}{|c|}{ Kelompok Kontrol } \\
\hline & & SY & $\mathbf{Y}$ & TY & STY & $\% \mathrm{~K}^{*}$ & SY & $\mathbf{Y}$ & TY & STY & $\% \mathrm{~K}^{*}$ \\
\hline \multirow{2}{*}{1} & $f$ & 13 & 65 & 65 & 13 & \multirow{2}{*}{62.5} & 12 & 63 & 62 & 31 & \multirow{2}{*}{58,3} \\
\hline & $\%$ & 8 & 42 & 42 & 8 & & 7 & 38 & 37 & 18 & \\
\hline \multirow{2}{*}{2} & $f$ & 18 & 46 & 4 & 7 & \multirow{2}{*}{66} & 16 & 40 & 50 & 20 & \multirow{2}{*}{60,3} \\
\hline & $\%$ & 16 & 39 & 39 & 6 & & 13 & 32 & 40 & 15 & \\
\hline \multirow{2}{*}{3} & $f$ & 9 & 48 & 46 & 14 & \multirow{2}{*}{61,2} & 7 & 47 & 51 & 21 & \multirow{2}{*}{57,9} \\
\hline & $\%$ & 8 & 41 & 39 & 12 & & 5 & 37 & 40 & 18 & \\
\hline \multirow{2}{*}{4} & $f$ & 12 & 45 & 18 & 3 & \multirow{2}{*}{71,1} & 11 & 44 & 23 & 6 & \multirow{2}{*}{67,8} \\
\hline & $\%$ & 15 & 58 & 23 & 4 & & 13 & 52 & 27 & 8 & \\
\hline
\end{tabular}

Keterangan: $\% \mathrm{~K}^{*}=$ total persentase keseluruhan berdasarkan indikator

Presentase keyakinan kemandirian belajar siswa kelompok pada indikator 1, yang menyatakan sangat yakin yaitu sebesar 8\%, sedangkan kelompok kontrol 7\%. Perbedaan persentase antara kedua kelompok sangat kecil. Hal ini juga terjadi pada siswa yang menjawab tidak yakin dan yakin, dimana siswa kelas eksperimen yang menjawab tidak yakin 5\% lebih sedikit dan jawaban yakin 4\% lebih tinggi dari kelompok kontrol.. Selanjutnya siswa yang menjawab tidak yakin, kelas eksperimen lebih rendah 10\% daripada kelompok kontrol. Secara keseluruhan siswa yang menjawab sangat yakin dan yakin digolongkan siswa sudah memiliki keyakinan kemandirian dalam menyelesaikan tugas terkait indikator 1 , sedangkan siswa yang menjawab tidak yakin dan sangat tidak yakin digolongkan belum memiliki keyakinan dalam kemandirian belajar. Sehingga dapat disimpulkan bahwa pada kelompok eksperimen sebagian siswa sudah memiliki keyakinan kemandirian (50\%) dalam menyelesaikan tugas indikator 1. Sedangkan siswa kelompok kontrol belum sepenuhnya memiliki keyakinan belajar belajar, terlihat dari persentase yang diperoleh sebesar $45 \%$.

Selanjutnya, untuk indikator kedua, dapat disimpulkan bahwa pada kelompok eksperimen sebagian siswa sudah memiliki keyakinan kemandirian (55\%) dalam menyelesaikan tugas indikator 2. Sedangkan siswa kelompok kontrol belum sepenuhnya 
memiliki keyakinan belajar belajar, terlihat dari persentase yang diperoleh sebesar $45 \%$. Selanjutnya, untuk indikator ketiga, dapat disimpulkan bahwa pada kelompok eksperimen dan kelompok kontrol belum sepenuhnya siswa memiliki keyakinan kemandirian dalam menyelesaikan tugas indikator 3 dimana masing-masingnya $49 \%$ dan $42 \%$. Selanjutnya, untuk indikator keempat, dapat disimpulkan bahwa pada kelompok eksperimen dan kelompok kontrol sebagian besar siswa sudah memiliki keyakinan kemandirian dalam menyelesaikan tugas indikator 4 dimana masing-masingnya $73 \%$ dan $65 \%$.

Secara keseluruhan, hasil dari data persentase kelompok eksperimen dan kelompok kontrol sebagian besar siswa sudah memiliki keyakinan kemandirian dalam mengerjakan tugas-tugas terkait kemampuan penalaran dan komunikasi matematis. Hal ini terlihat dari persentase yang diperoleh siswa per indikator di atas 50\%. Untuk lebih jelasnya berikut disajikan persentase keyakinan kemandirian belajar siswa berdasarkan indikator pada kelompok eksperimen dan kelompok kontrol.

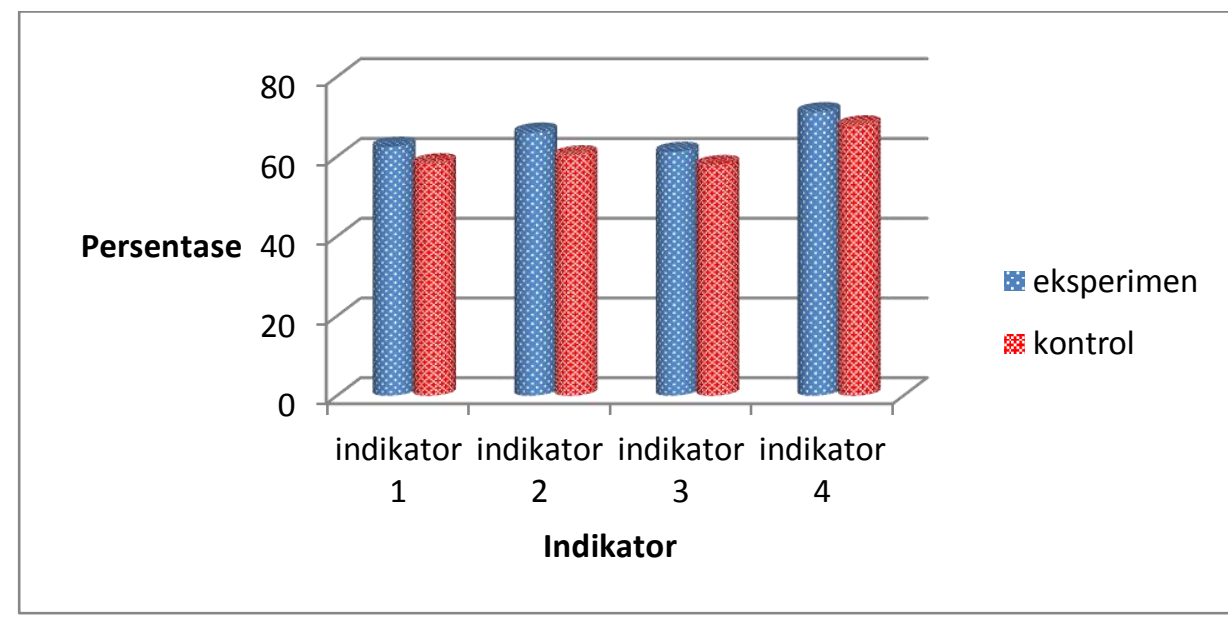

\section{Gambar 2}

Perbandingan Persentase Keyakinan Kemandirian Belajar Siswa

Berdasarkan Gambar 2 terlihat bahwa proporsi keyakinan kemandirian belajar siswa kelompok eksperimen dan kelompok kontrol tidak jauh berbeda berdasarkan indikatornya. Hal ini didukung juga oleh hasil uji perbedaan dua proporsi bahwa tidak terdapat perbedaan proporsi keyakinan kemandirian belajar siswa yang belajar melalui penemuan terbimbing dengan siswa yang belajar melalui pembelajaran konvensional. 


\section{KESIMPULAN}

Hasil penelitian ini menunjukkan bahwa tidak terdapat perbedaan proporsi keyakinan kemandirian belajar yang signifikan antara siswa yang belajar melalui pembelajaran penemuan terbimbing dengan siswa yang belajar melalui pembelajaran konvensional. Selanjutnya perbandingan persentase capaian per indikator, diperoleh proporsi keyakinan kemandirian belajar siswa kelompok eksperimen dan kelompok kontrol tidak jauh berbeda satu dengan lainnya.

\section{DAFTAR PUSTAKA}

Darr, C. \& Fisher, J. (2004). Self-Regulated Learning in the Mathematics Class [Online]. Tersedia: http://www.nzcer.org.nz//pdfs/13903.pdf.

Joet, et.al. (2011). Sources of Self-Efficacy: An Investigation of Elementary School Students in France. Journal of Educational Psychology. 103(3), hlm. 649-663.

Joo, et.al. (2000). Self-Efficacy for Self-Regulated Learning, Academic Self-Efficacy, and Internet Self-Efficacy in Web Based Instruction. Educational Technology Research and Development. 48(2), hlm 5-17.

Rooney, C. (2009). How am I Using Inquiry-Based Learning to Improve My Practice and to Encourage higher Order Thinking Among My Students of Mathematics?. Education Journal of Living Theories. 5 (2), hlm. 99-127.

Rusefendi, E. T. (2010). Dasar-Dasar Penelitian Pendidikan dan Bidang Non Eksakta Lainnya. Bandung: Tarsito.

Sumarmo, U. (2013). Kumpulan Makalah: Berpikir dan Disposisi Matematik serta Pembelajarannya. FPMIPA UPI: Bandung.

Tilmam, K.J \& Weiss, M (2000). Self-Regulated Learning as cross-Curriculer Conpetence (PISA) [Online]. Tersedia: http://www.pisa.no/pdf/ turmoionste2004.pdf.

Trianto. (2007). Model - Model Pembelajaran Inovatif Berorientasi Konstruktivistik. Jakarta : Prestasi Pustaka.

Usher, et.al. (2011). Sources of Self-Efficacy: An Investigation of Elementary School Students in France. Journal of Educational Psychology. 103 (3), hlm 649-663.

Usher, E. L \& Pajares Frank. (2008). Self-Efficacy for Self-Regulated Learning: a Validation Study. Educational and Psychological Measurement. 68(3), hlm 443-463.

Zimmerman, B. J. (2002). Becoming a Self Regulated Learner: an Overview. Theory Into Practice. 41, hlm 64-70 